\title{
Racionalidade neoliberal e Ensino Médio: por onde trilhar o equilíbrio difícil para pensar o currículo?
}

\begin{abstract}
Resumo:
O texto, de caráter ensaístico, se propõe a pensar sobre o currículo do Ensino Médio em interface com a atual Reforma (Lei no 13.415/2017) (BRASIL, 2017). Partimos de dois pressupostos: a) é inegável que na sociedade em que vivemos - da cultura da oferta e do novo capitalismo -, temos a necessidade de pensarmos um novo currículo para o Ensino Médio, de forma de que um currículo flexível, com a possibilidade de escolha aos jovens parece interessante. b) a dimensão do itinerário formativo acaba por precarizar o sujeito, ao passo que produz e reproduz desigualdades ao não pensar um currículo com centralidade no conhecimento e no direito ao acesso a esse conhecimento para todas as juventudes, e que ao mesmo tempo estimula a individualização e um protagonismo juvenil que acaba por ser convertido na formação de um neo-sujeito empresário de si mesmo. Por fim a luz dos referenciais estudados, propomos uma postura de "equilibrio difícil" a qual nos ajude a pensar o currículo conectado às juventudes no nosso tempo o qual seja: comum, inclusivo, de formação integral, cooperativo e comprometido com a produção crítica e criativa de valiosos projetos de vida.
\end{abstract}

\section{Palavras-chave:}

Currículo. Ensino Médio. Juventudes. Equilíbrio difícil.

\section{Neoliberal rationality and High School: where to find the difficult balance to think about the curriculum?}

\begin{abstract}
The text, of an essayistic nature, proposes to think about the teaching curriculum in interface with the current Reform (Law no. 13.415/2017) (BRASIL, 2017). We start from two assumptions: a) it is undeniable that in society and that we live - from the culture of offer and a new capitalismo-, we need to think about a new curriculum for High School, so that a flexible curriculum, with the possibility of choice for young people seems interesting. b) the dimension of the formative itinerary ends up making the subject precarious, while it produces and reproduces inequalities by not thinking of a curriculum with centrality in knowledge and in the right to access that knowledge for all youths, which at the same time encourages
\end{abstract}

\footnotetext{
1 Doutoranda em Educação pela Universidade do Vale do Rio dos Sinos, Professora da Rede Estadual e Municipal de ensino em Santo Ângelo (RS). E-mail: luthimv@hotmail.com. ORCID iD: http://orcid.org/0000-0001-5619-9029.

2 Doutoranda em Educação pela Universidade do Vale do Rio dos Sinos, Vice-Diretora Educacional do Colégio Marista Champagnat. E-mail: shirley.cardoso@maristas.org.br. ORCID iD: http://orcid.org/0000-0003-0628-756X.
} 
individualization and a youthful protagonism that ends up being converted into the formation of a new subject of himself. Finally, in light of the studied references we propose a posture of "difficult balance" which helps us to think about the curriculum connected to youth in our time, which is: common, inclusive, of integral formation, cooperative and committed to the critical and creative production of valuable life projects.

Keywords: Curriculum. High school. Youths. Difficult balance.

\section{Racionalidad neoliberal y bachillerato: ¿dónde encontrar el difícil equilibrio para pensar el currículo?}

Resumen: El texto, de carácter ensayístico, propone pensar el currículo de la Enseñanza en interfaz con la actual Reforma (Ley no 13.415/2017) (BRASIL, 2017). Partimos de dos supuestos: a) es innegable que en la sociedad y que vivimos - desde la cultura de la oferta y un nuevo capitalismo -, tenemos la necesidad de pensar en un nuevo currículo para el Bachillerato, por lo que parece interesante un currículo flexible, con posibilidad de elección para los jóvenes. b) la dimensión del itinerario formativo termina precarizando al sujeto, en tanto que produce y reproduce desigualdades al no pensar en un currículo con centralidad en el conocimiento y el derecho de acceso a este conocimiento para todos los jóvenes, y que al mismo tiempo estimula la individualización y un protagonismo juvenil que termina convirtiéndose en la formación de un nuevo sujeto empresario de sí mismo. Por fin, a la luz de los referentes estudiados proponemos una postura de "difícil equilibrio" que nos ayude a pensar en el currículo vinculado a los jóvenes de nuestro tiempo y que sea: común, inclusivo, de formación integral, cooperativo y comprometido con la producción crítica y creativa de proyectos de vida valiosos.

Palabras clave: Currículo escolar. Enseñanza secundaria. Juventud. Difícil equilibrio.

Ninguém tira o trono do estudar Ninguém é o dono do que a vida dá

E nem me colocando numa jaula Porque sala de aula essa jaula vai virar A vida deu os muitos anos da estrutura Do humano à procura do que Deus não respondeu

Deu a história, a ciência, arquitetura

Deu a arte, deu a cura e a cultura pra quem leu Depois de tudo até chegar neste momento me negar Conhecimento é me negar o que é meu Não venha agora fazer furo em meu futuro Me trancar num quarto escuro e fingir que me esqueceu Vocês vão ter que acostumar [...]

Dani Black

\section{Currículo do Ensino Médio: entre transformações e precarização dos sujeitos}

"Ninguém tira o trono de estudar, ninguém é dono do que a vida dá" destaca a música o $O$ Trono do Estudar, composta por Dani Black (O TRONO, 2015) e gravada por diversos artistas da $\mathrm{MPB}$, que se tornou um hino de resistência, muitas vezes cantada nas ocupações das escolas no 
final de 2015 em protesto ao processo de fechamento destes educandários, em São Paulo, pelo então governador. Alguns anos após as ocupações, a música é, ainda hoje, considerada um hino em defesa da educação no Brasil, especialmente pelos jovens estudantes do Ensino Médio. Dessa forma, essa composição nos provoca a pensar várias questões relacionadas às juventudes, ao Ensino Médio e, mais especificamente, ao currículo. Ao utilizar o termo "trono do estudar", a música atribui à educação e ao seu acesso um lugar de destaque e suma importância e nos possibilita estabelecer reflexões sobre a atual Reforma do Ensino Médio - estabelecida pela Lei no 13.415/2017 (BRASIL, 2017), que faz mudanças estruturais no currículo desta etapa da educação básica, dentre as quais escolhemos dialogar nesse momento, qual seja: a questão dos itinerários formativos e a anunciada liberdade de escolha. Quais seriam os desdobramentos dessa aposta na autonomia juvenil? Se "me negar conhecimento é me negar o que é meu" (O TRONO, 2015), de qual conhecimento estamos falando quando pensamos o Ensino Médio em nosso país? Ou ainda: qual Ensino Médio e qual currículo de Ensino Médio propomos para as nossas juventudes?

Nesse sentido, nos propomos a pensar a atual reforma do Ensino Médio por duas perspectivas: a primeira é a que é inegável que, na sociedade em que vivemos, caracterizada por Bauman (2010) e Sennett (2006) como a sociedade da cultura da oferta e um novo capitalismo, temos a necessidade de pensarmos um novo currículo para o Ensino Médio. A segunda é que a dimensão do itinerário formativo poderá precarizar o sujeito, ao passo que produz e reproduz desigualdades ao não pensar um currículo com centralidade no conhecimento e no direito ao acesso a esse conhecimento para todas as juventudes; estimula a individualização e um protagonismo juvenil que acaba por ser convertido na formação de um neo-sujeito empresário de si mesmo, características que podem ser encontradas em uma sociedade na qual impera a racionalidade neoliberal denominada por Dardot e Laval (2016, p. 17):

o neoliberalismo antes de ser uma ideologia ou uma política econômica, é em primeiro lugar e fundamentalmente uma racionalidade e, como tal, tende a estruturar e organizar não apenas os governantes, mas até a própria conduta dos governados.

\section{A cultura da oferta e a inegável necessidade de mudanças}

Em seu texto A cultura da oferta, Bauman (2010) começa nos dizendo que na fase líquido-moderna em que vivemos a "cultura é feita na medida de escolha individual (voluntária ou imposta por obrigação), é destinada a servir as exigências da liberdade" (BAUMAN, 2010, p. 35); assim, esse indivíduo jovem, estudante, é o sujeito dessa cultura da oferta, recebendo o direito de ser o único administrador da "política da vida”. Nesse sentido, é compreensível o cenário que o Novo Ensino Médio propõe: uma organização curricular mais flexível, que contemple uma Base Nacional Comum Curricular (BNCC) (MEC, 2018) e a oferta de diferentes possibilidades de escolhas aos estudantes, os itinerários formativos, com foco nas áreas de conhecimento e na formação técnica e profissional. As próprias propagandas vinculadas no Twitter e em outras redes sociais apresentaram fortemente um discurso de escolha, flexibilização, protagonismo, mostrando o que o autor nos alerta ser uma cultura de oferta, não de normas, em que "as redes substituem as estruturas em um jogo de apego/desapego e uma infinita sucessão de conexões e desconexões substituem a atividade de 'determinar' e 'fixar"' (BAUMAN, 2010, p. 36).

A cultura da oferta, própria da modernidade líquida, nos possibilita compreender que uma proposta curricular que se ampare na ideia de liberdade de escolha do indivíduo parece vir a responder às demandas de uma sociedade fortemente amparada nos princípios neoliberais. É nesse sentido que o autor afirma:

abandonar os padrões muito rígidos, ser condescendente com a falta de critérios, satisfazer todos os gostos sem privilegiar nenhum deles, promover a inconsistência e a flexibilidade e 
exaltar a instabilidade e a incoerência, esta é, portanto, a estratégia justa (a única razoável?) hoje. (BAUMAN, 2010, p. 34).

É nessa direção que se estrutura a atual proposta de Ensino Médio, fortemente vinculada nas redes sociais, televisão e demais mídias, aprovada através de medida provisória que alterou a atual Lei de Diretrizes e Bases da Educação Nacional (Lei no 9394/1996) (BRASIL, 1996), e que se encontra em processo de implementação. Tem chegado às escolas levando sempre o forte argumento da participação, flexibilização e da liberdade de escolha, quando diz que cada comunidade poderá escolher os itinerários formativos que irá ofertar, construindo Referenciais Curriculares que amparem a proposta de cada Estado e cada município - como é caso do Rio Grande do Sul, onde desde os primeiros meses do ano letivo de 2019 tem desenvolvido estudos da proposta, sugerindo o preenchimento de um questionário semiestruturado ${ }^{1}$, o qual induza o reconhecimento da necessidade de mudanças, bem como do fracasso das escolas na estrutura que até então vinham reproduzindo, mas, ao mesmo tempo, não proporciona muitas possibilidades para que os educadores possam opinar e discordar da proposta que está em pauta. Esse mesmo Estado escolheu, no ano de 2020, trinta escolas piloto para iniciar a reforma. Essas escolas viveram o cenário de mudanças em meio a pandemia de Coronavírus, aumentando ainda mais as dificuldades de operacionalização, de diálogo e de enfrentamentos da comunidade escolar diante da proposta.

No guia de implementação do Novo Ensino Médio organizado pelo Ministério da Educação, encontra-se os seguintes argumentos quanto aos benefícios dessa nova organização curricular: atende as necessidades dos jovens; favorece o protagonismo uma vez que o jovem poderá escolher o itinerário formativo; o jovem terá acesso a formação geral e depois a formação específica nas áreas que se identificam; terá acesso a formação técnica e profissional e que tudo isso melhorará sua permanência e resultados de aprendizagem.

Longe de fazermos uma escrita puramente crítica e que não reconheça a realidade do nosso tempo, reconhecemos aqui, desde o início do nosso texto, a necessidade de uma reforma curricular, da necessidade de maior diálogo com as necessidades de nossas juventudes e que estes, mesmo os mais pobres, precisam de uma "cualificácion de toda la ciudadanía para que este em condiciones de competir - y contribuir - em uma economia global" (ENQUITA, 2017, p. 33). Dialogando com Enguita, destacamos que os dilemas de nosso tempo são outros e que o currículo do Ensino Médio precisa levar em consideração esse novo cenário que o autor denominou de "la información e de la globalización", precisando de uma formação que deixe o sujeito em condições de competir no mercado de trabalho, no que destacamos:

No digo que la educación no deba incluir las dimensiones social, política, artística, emocional, deportiva, etc., sino que está muy lejos de ser integral, favorecer un desarrollo personal completo, contribuir a asegurar la ciudadanía plena precisamente por lo contrario de lo que suelen suponer las profesiones que viven de ella, es decir, por su alejamiento del mundo del trabajo, por su ignorancia de las coordenadas económicas, por sus rituales de pureza y no contaminación frente al ineludible mundo de la economia. (ENGUITA, 2017, p. 28).

Precisamos, sim, olhar criticamente para essa proposta de reforma de currículo, pois tememos que, se assim implementada, será possível afirmar, nas palavras de Enguita "potencialmente, la cualificación tiene uma enorme capacidade de produzir desigualdade” (ENGUITA, 2017, p. 28).

1 Encontra-se disponível no site da SEDUC-RS o questionário que aqui referimos. Foi respondido por educadores, estudantes e comunidade escolar e que poder acessado no seguinte endereço: http://formularios.educacao.rs.gov.br/. Acesso em: 2 out. 2020. 


\section{Os itinerários formativos e o empresariamento de si mesmo: a racionalidade neoliberal no currículo do Novo Ensino Médio}

Iniciamos o segundo momento de nossa discussão levantando a reflexão de que um currículo, pautado na flexibilidade, na liberdade dos sujeitos escolherem, deve, necessariamente, oportunizar o conhecimento cientificamente construído pela humanidade, devendo ser oferecido a todos independente da sua condição social, econômica ou cultural. Um currículo, ao inclinar-se fortemente para uma formação técnica e profissional, lesa a formação científica. Um currículo que é fortemente amparado na escolha individual produz figuras cada vez mais individualizadas e precárias. Nessa esteira, dizemos que este é um currículo que, dentro de uma racionalidade neoliberal, produz empresários de si mesmos, como podemos compreender nas palavras de Dardot e Laval (2016, p. 16):

O neoliberalismo não destrói apenas regras, instituições, direitos. Ele também produz certos tipos de relações sociais, certas maneiras de viver, certas subjetividades. Em outras palavras, com o neoliberalismo o que está em jogo é nada mais nada menos que a forma de nossa existência, isto é, a forma como somos levados a nos comportar, a nos relacionar com os outros e com nós mesmos. [...] Essa norma impõe a cada um de nós que vivamos num universo de competição generalizada, intima os assalariados e as populações a entrar em luta econômica uns contra os outros, ordena as relações sociais segundo o modelo do mercado, obriga a justificar desigualdades cada vez mais profundas, muda até o indivíduo, que é instado a conceber a si mesmo e a comportar-se como uma empresa.

O indivíduo que, transformado pela racionalidade neoliberal que o interpela a conceber a si mesmo, comportando-se como uma empresa, pode ser facilmente percebido em nossos sujeitos do Ensino Médio: a escolha do seu itinerário formativo nada mais é que um empresariamento de si mesmo, do seu futuro, de seus sonhos e, mais especificamente, numa proposta com caráter altamente técnico e voltado para as habilidades que tem em seu cerne o saber-fazer, deixando aquém o saber-conhecer. Esse sujeito, cada vez mais individualizado pelo processo de escolha e pela racionalidade em que está imerso, é desafiado a jogar esse jogo (onde não lhe é permitido escolher se quer jogar ou não), sendo um" jogo do qual todos têm de participar, um jogo competitivo, um jogo entre desiguais" (VEIGA-NETO, 2018, p. 39). Essa metáfora do jogo nos ajuda a compreender as desigualdades geradas por essa liberdade de escolha, em que se perdeu de vista o direito aos conhecimentos como referência, onde desiguais competem em um mesmo cenário, sem que todos tenham as ferramentas necessárias para competir, o que nos leva a pensar a partir das palavras do autor citado acima:

Ter maior ou menor sucesso no jogo é uma questão da competência, dedicação, interesse e garra de cada jogador. É claro que sempre tais atributos variam de jogador. Um jogo só faz sentido se nenhum jogador for idêntico a qualquer outro e ninguém abandonar o jogo. Sempre é necessário existir, por menor que seja, um diferencial entre os participantes. A competição é, assim, a manifestação factual desse diferencial; os sucessos e fracassos são a manifestação material. (VEIGA-NETO, 2018, p. 38).

Quais são as características, os riscos, as consequências de jogar esse jogo competitivo? Quais são essas subjetividades produzidas, anunciadas por Dardot e Laval (2016)? Buscando outros elementos analíticos para pensarmos sobre essas figuras subjetivas produzidas pela racionalidade neoliberal, e por esse jogo entre desiguais, apresentamos brevemente as quatro figuras subjetivas de Hardt e Negri (2014): o "endividado", o "mediatizado", o "secutirizado" e o "representado".

O "endividado" é uma figura que faz parte de uma realidade que "ter dívidas está se tornando a condição geral da vida social” (HARDT; NEGRI, 2014, p. 22); um ser controlado pela dívida, esse 
sujeito não tem apenas dívidas financeiras, está em dívida com o trabalho, com a família, com seus amigos, com as atividades da vida que deveria, mas não conseguiu realizar. Este é o jovem que poderíamos pensar em dívida com seus estudos, com os trabalhos escolares, com a falta de tempo para a família e para os amigos, em dívida futuras; ele tem dívida com a continuidade dos seus estudos, com a sua profissão, com a constituição da sua própria vida.

O "mediatizado" representa aqueles sujeitos "sufocados pelo excesso de informação, uma subjetividade que, não é nem ativa nem passiva, mas constantemente absorvida em atenção" (HARDT; NEGRI, 2014, p. 28-29). Nisso, localizamos as nossas juventudes imersas em uma enxurrada diária de informações e redes sociais que a todo momento os interpelam a ter algo a dizer, sem ter espaço para "respirar", pensar e encontrar algo de qualidade a ser dito: "não é a quantidade de informação, comunicação e expressão, mas, sim, sua qualidade (HARDT; NEGRI, 2014, p. 28).

O "securitizado": a figura que vive dominado pelo medo, acaba enxergando como positiva uma sociedade que cria cada vez mais meios de vigilância e controle, que lhes são oferecidos como garantias de segurança, assim "o medo é a motivação básica do securitizado para aceitar não só se papel duplo - vigia e vigiado - no regime de vigilância" (HARDT; NEGRI, 2014, p. 38). E, nessa figura, podemos identificar os nossos jovens com o medo de sair à rua, o medo de não conseguir trabalho, de não ser alguém, de não ser feliz, o medo de não dar conta, o medo da solidão, de forma que nesse regime de segurança "o medo é um significante vazio, no qual todos os tipos de fantasmas amedrontadores podem aparecer" (HARDT; NEGRI, 2014, p. 39). O "representado", ainda, é o sujeito que "atua na sociedade destituído de inteligência e manipulado pela imbecilidade ensurdecedora do circo midiático" (HARDT; NEGRI, 2014, p. 42); seria o sujeito que, enganado pela mídia e outros meios de dominação, deixa de participar democraticamente das construções sociais, acredita no que lhe é dito, sendo muitas vezes dominado por formas autoritárias de governar.

As figuras subjetivas de Hardt e Negri (2014), o jogo competitivo, inevitável e desigual de Veiga-Neto (2018) e o empresário de si mesmo de Dardot e Laval (2016) tecem uma lupa analítica sobre o sujeito precário que aqui nos propomos analisar: o jovem estudante do Ensino Médio, que tem sua subjetividade moldada por uma racionalidade neoliberal que oferece a este uma ideia de livre escolha, protagonismo, participação e flexibilidade, porém que, em muitos pontos, nega o conhecimento que lhe é de direito - como diz a música escolhida no início de nossa reflexão (O TRONO, 2015). A história, a ciência, a arquitetura e a cultura representam os conhecimentos desse currículo, um currículo que, de forma a garantir a justiça social, deveria partir do pressuposto de que é um direito o acesso a todos os conhecimentos, e não uma parte deles, como propõe os itinerários formativos e é nesse ponto que adensamos a nossa crítica dialogando com Frigotto e Ramos (2016).

Os autores, ao nomearem criticamente essa reforma como uma "contrarreforma" do Ensino Médio, apresentaram alguns questionamentos para fundamentarem essa crítica:

que jovens disseram que se interessam por este tipo de escola? Que jovens se interessam por tão pouco? Querem a metade da educação a que eles têm direito? Quem disse que os jovens não se interessam pelo ensino de ciências, de artes, de filosofia, de sociologia, de educação física, de história da África [...]. (FRIGOTTO; RAMOS, 2016, p. 41).

O cerne da contra-reforma está na dissociação entre ensinar e educar e na condução de um processo de ensino com base na fragmentação e no pragmatismo. Reitera e incorpora as medidas dos períodos autoritários, sob ditaduras ou não, que afirmaram, ao longo do Século $\mathrm{XX}$, a dualidade educacional e o acesso desigual ao conhecimento e à cultura, de acordo com a classe social. (FRIGOTTO; RAMOS, 2016, p. 37).

Frigotto e Ramos (2016) destacam como a racionalidade neoliberal encontra-se presente na proposta do Novo Ensino Médio e como esta produz desigualdade no acesso ao conhecimento. Eles destacam seu caráter autoritário de implementação, bem como seu caráter fortemente 
técnico e pragmático, de certa forma descompromissado ou que não prioriza um currículo pautado nos conteúdos e no conhecimento - como direito e nos processos democráticos como as melhores formas de pensar o viver em sociedade - e os projetos educativos para as nossas juventudes, como podemos observar:

\begin{abstract}
Vê-se, assim, o caráter manipulatório da publicação antecipada da MP em relação à conclusão da BNCC, dada a influência de seu conteúdo pelo ideário conservador da MP, a qual foi convertida no Projeto de Lei no 34/2016. Trata-se, assim, de um movimento que tem na caneta do executivo a sua objetividade, mas na verdade representa a vontade de conservadores na sociedade brasileira. A contra-reforma é expressão do pensamento conservador, valendo-se de uma lógica economicista e pragmática expressiva de nosso capitalismo dependente, em um tempo de hegemonia neoliberal e cultura pós-moderna; a cultura do fragmento, do imediato, do utilitário e do enxuto. Trata-se de uma política que liofiliza a educação básica retirando-lhe conteúdo de formação científica e ético-política que se esperaria numa sociedade que tem as pessoas e não o mercado como a razão da política pública. (FRIGOTTO; RAMOS, 2016, p. 37).
\end{abstract}

Os autores aqui mencionados nos levam a compreender que o cerne na Reforma do Ensino Médio se ampara numa racionalidade neoliberal que, muito bem definida por Frigotto e Ramos (2016), faz parte da cultura do imediato, do utilitário e do enxuto, preocupando-se muito mais com uma formação pragmática voltada à inserção no mercado de trabalho, produzindo desigualdades ao propor um acesso desigual ao conhecimento. Quais seriam os caminhos para pensarmos o currículo do Ensino Médio em que se desfaça a ordem neoliberal que "captura as subjetividades singulares transformando-as em fonte de capitalização de si, segundo o modelo do capital humano" (RAGO, 2018, p. 133).

Mesmo olhando como a racionalidade neoliberal afeta especialmente as mulheres e o movimento feminista, as alternativas que Rago (2018) apresenta nos parecem um primeiro caminho para chegarmos ao que Sacristán (2017) denominou de um equilíbrio difícil: pensar um currículo que leve em conta a realidade, os interesses e as demandas juvenis, mas que ao mesmo tempo conserve (sem ser simplesmente conservador e meramente conteudista) um conjunto de conteúdos e de formação científica a ser ofertado a todos os jovens das diversas realidades de Ensino Médio. Assim, os pressupostos de Gómez (2017), em seu texto "Aprender a pensar para poder elegir", nos parecem alternativas para pensarmos o currículo do Ensino Médio. É sobre estes caminhos e alternativas que discorreremos a seguir.

\title{
Caminhos para pensar um currículo do Ensino Médio: a cultura do comum e a produção de novas formas de existência
}

Rago (2018) aposta na construção de novos modos de subjetivação que "lutem contra processos normalizadores", que afirmem a vontade sobre si mesmos, buscando "constituírem-se subjetivamente a partir de seus próprios olhares e interpretações" e que invista, na amizade, "nas relações não hierárquicas e respeitem as diferenças" (RAGO, 2018, p. 136). A autora nos impulsiona a produzir alternativas ao neoliberalismo apontando formas de convivência menos individualizantes, mais humanas, cooperativas e compreensivas. Não é isso que devemos buscar como parte essencial na proposta de currículo para as nossas juventudes?

Ao buscar o difícil equilíbrio, Sacristán (2017) ressalta o dilema entre a importância das experiências e dos conteúdos vinculados à vida e a importância de um currículo pautado nos conhecimentos:

Un contenido es valioso si la experiencia que pueda provocar em el sujeto que aprende tiene las características de relevancia, si enlaza con otras experiencias, si proporciona información nueva 
y novedosa, si reorganiza la información, si desencadena aprendizajes transferibles a situaciones diversas, si se obtiene alguna gratificación; es decir, si son motivantes. (SACRISTÁN, 2017, p. 23).

Ao buscar esse equilíbrio e uma política de currículo, o autor nos apresenta alternativas e uma definição para pensar um currículo que:

Potencie una educación integral, abierta al mundo de la información, que tome em consideración las nuevas posibilidades (sin dejarse llevar por los apocalípticos ni por los panegiristas integrados) propiciando el gusto por el saber en un mundo inundado de mensajes atractivos, pero también em muy buena medida alienantes y significativos. (SACRISTÁN, 2017, p. 24).

Desse modo, ao pensar na educação integral, aberta ao mundo da informação e que leve em consideração as novas possibilidades - de forma que iniciamos o texto afirmando as necessidades de uma reforma de currículo e de pensar a escola de Ensino Médio -, os pressupostos apresentados por Sacristán (2017, p. 24-26) nos parecem importantes para pensar o currículo do Ensino Médio: nenhum conteúdo se justifica por si mesmo, de forma que eles têm a ver com os valores que defendemos e devem contribuir com o desenvolvimento pessoal, com a construção da autonomia intelectual e para o bem comum; os valores dos conteúdos estão na sua capacidade de desenvolver ricos processos de aprendizagem levando o sujeito a pensar; as dimensões do espaço-tempo precisam ser cuidadosamente pensadas na escolha da metodologia ao refletir as questões curriculares; a escola deve seguir transmitindo a informação, informação essa pensada como um saber organizado e compreensível, um conhecimento novo.

Nessa mesma direção de Sacristán (2017), Gómez (2017, p. 72-74) nos apresenta outros pressupostos que entendemos serem complementares para pensar o currículo, que denominou de uma "nova pedagogia", e que, levando em consideração as novas realidades, demandas e contextos das escolas e das juventudes, nos parecem caminhos possíveis para serem trilhados na busca da resposta para: qual currículo para o Ensino Médio? Utilizando dos pressupostos do autor, desafiamos a pensar um currículo que "ayude a cada indivíduo a construirse de manera singular y creativa" (GÓMEZ, 2017, p. 72) e busque um currículo que compreenda que menos é mais e melhor, buscando menor extensão e maior profundidade; que possibilite primeiro as experiências e depois as formalizações, utilizando a vida cotidiana para interpretar, tomar decisões, guiar a atuação docente e avaliar os processos e resultados destes; leve em consideração que se pode aprender fazendo, proporcionando projetos, estratégias e experiências; que priorize a cooperação e desenvolva um clima de confiança onde o processo de aprendizagem cooperativo saiba valorizar os talentos e os diferentes olhares de cada indivíduo; que saiba promover outras metodologias de ensino como a utilização dos recursos digitais, as redes sociais, a sala de aula invertida e as diferentes metodologias; que proporcione mais momentos de avaliação da prática educativa, mais ajuda, orientação e mais apoio, de forma a diminuir a qualificação fria, externa, distante e seletiva; que potencialize a função de tutor do professor, para que este ajude a aprender de forma que cada sujeito construa disciplinada, crítica e criativamente o seu próprio projeto acadêmico, pessoal e profissional, especialmente para aqueles que em diversas circunstâncias, em uma sociedade cada vez mais desigual, não sabem, não podem e não querem aprender aquilo que a escola exige.

Dialogando com Dardot e Laval (2016), Rago (2018), Veiga-Neto (2018), Sacristán (2017) e Gómez (2017), reafirmamos o que dissemos inicialmente: vivemos em tempos em que o Ensino Médio necessita de uma reforma de currículo que dialogue com as necessidades das juventudes e da realidade do nosso tempo. Esse currículo precisa ser pensado a partir de alternativas que impulsionem novas formas de existir, alternativas para desfazer a lógica do empresariamento de si mesmo e que, segundo os autores aqui escolhidos, perpassam pelos caminhos de um equilíbrio difícil. Portanto, um currículo que considere as experiências juvenis, mas que essencialmente construa-se em patamares nos quais o conhecimento científico se embase fortemente e proporcione os elementos necessários para a construção de um rico projeto de vida. 
É consenso entre autores a necessidade de práticas mais cooperativas e menos individualizantes, que respeitem as diferenças, como espaço privilegiado da soma e do aprender. Um currículo que possibilite novas práticas e experiências, dando liberdade para pensar e criar. Nos encaminhando para a conclusão da nossa reflexão, os caminhos mais justos para serem trilhados são aqueles que possam ser pensados com e para o comum. Utilizando as palavras de Dardot e Laval (2016), precisamos pensar um currículo comum, inclusivo, de formação integral, cooperativo e comprometido com a produção crítica e criativa de valiosos projetos de vida:

As práticas de 'comunização' do saber, de assistência mútua, de trabalho cooperativo podem indicar os traços de outra razão do mundo. Não saberíamos designar melhor essa razão alternativa senão pela razão do comum. (DARDOT; LAVAL, 2016, p. 402).

Que as alternativas aqui delineadas e os desafios de produzir novas formas de existência possam ser guiados por outra razão do mundo e que esta nos ajude a encontrar outras formas de produzir um currículo para as nossas juventudes que lhes garanta "o trono do estudar".

\section{Referências}

BAUMAN, Zygmunt. Capitalismo parasitário. Rio de Janeiro: Zahar, 2010.

BRASIL. Lei no 13.415, de 16 de fevereiro de 2017. Altera as Leis no 9.394, de 20 de dezembro de 1996 [...]. Brasília, DF: Presidência da República, [2017].

BRASIL. Lei no 9.394, de 20 de dezembro de 1996. Estabelece as diretrizes e bases da educação nacional. Brasília, DF: Presidência da República, [1996].

DARDOT, Pierre; LAVAL, Christian. A nova razão do mundo: ensaio sobre a sociedade neoliberal. São Paulo: Boitempo, 2016.

ENGUITA, Mariano Fernández. La dinâmica del capital humano y los interfaces del nuevo entorno. In: SACRISTÁN, José Gimeno (comp.). Los contenidos, una reflexión necessária. 1. ed. São Paulo: Cortez, 2017. p. 27-33.

FRIGOTTO, Gaudêncio; RAMOS, Marise Nogueira. Medida Provisória 746/2016: a contra-reforma do Ensino Médio do golpe de estado de 31 de agosto de 2016. HISTEDBR On-line, Campinas, n. 70, p. 30-48, dez. 2016.

GÓMEZ, Ángel Pérez. Aprender a pensar para poder elegir. La urgência de uma nueva pedagogia. In: SACRISTÁN, José Gimeno (comp.). Los contenidos, una reflexión necessária. 1. ed. São Paulo: Cortez, 2017. p. 67-75.

HARDT, Michael; NEGRI, Antonio. Declaração: isto não é um manifesto. São Paulo: n-1 Edições, 2014.

MINISTÉRIO DA EDUCAÇÃO (MEC). Base Nacional Comum Curricular. Brasília, DF: MEC, 2018.

O TRONO do Estudar. [Compositor e intérprete]: Dani Black. Rio de Janeiro: 2015.

RAGO, Margareth. Empresárias de si mesmo? Recuso-me, denuncio! In: RESENDE, Haroldo de (org.). Michel Foucault: a arte neoliberal de governar e a educação. São Paulo: Intermeios; Brasília, DF: CAPES/CNPq, 2018. p. $127-142$.

SACRISTÁN, José Gimeno. La sustantividad educativa de los contenidos. Algunas obviedades que, al parecer, no lo son. In: SACRISTÁN, José Gimeno (comp.). Los contenidos, una reflexión necessária. 1. ed. São Paulo: Cortez, 2017. p. 17-26.

SENNETT, Richard. A cultura do novo capitalismo. Rio de Janeiro: Record, 2006.

VEIGA-NETO, Alfredo. Neoliberalismo e educação: os desafios do precariado. In: RESENDE, Haroldo de (org.). Michel Foucault: a arte neoliberal de governar e a educação. São Paulo: Intermeios; Brasília, DF: CAPES/CNPq, 2018. p. 33-44.

Data de submissão: 27/01/2021

Data de aceite: 12/02/2021 
648 >> Cadernos do Aplicação | Porto Alegre | jan.-jun. 2021 | v. 34 | n. 1 